\title{
INTRAUTERINE GROWTH RESTRICTION - AN IMPORTANT EPIGENETIC PREMISE FOR ADULT CARDIOVASCULAR DISEASES
}

\author{
$\begin{array}{lll}\text { M.A. MOGA } & & \text { S.I. BĂDILĂ } \\ & \text { D. FESTILĂ } & \\ & \end{array}$ \\ A. LĂCULICEANU ${ }^{1}$ C.P. PODAȘCĂ ${ }^{1}$
}

\begin{abstract}
Given multiple causalities, the fetus develops an intrauterine growth restriction that compensatory stimulates the adaptative phenomena; both, the determining cause of intrauterine growth restriction and the adaptative reactions, will initiate epigenetic changes which will affect the longterm structure and functionality of the heart and will modify the cardiovascular reactivity. The study is based on a systematic review of 20 existing studies that certifies a link between epigenetic changes and adult cardiovascular disease. Against the background of epigenetic changes, postnatal nutritional and behavioral factors are added which lead to pathologies in adult life, so the proper functioning and development of the body starts from the first moments of intrauterine life and contuse postnatal, creating the premises for a healthy life. However, it is difficult to assess the environmental factors that interact with the human body and how this combination of factors determines a predisposition to cardiovascular disease.
\end{abstract}

Key words: Intrauterine growth restriction, intrauterine programming, epigenetics, cardiovascular diseases

\section{Introduction}

The term "epigenetics" refers to the processes in which the expression of genes determines the individual phenotype, processes that have their beginning either in the gametogenesis phase or in the prenatal phase, these having a role in heredity and remaining stable throughout life. Epigenetics also involves mechanisms in which environmental factors, including maternal nutrition or exposure to certain chemicals during pregnancy, can influence the fetal

\footnotetext{
${ }^{1}$ Faculty of Medicine, Transilvania University of Brasov

${ }^{2}$ Faculty of Dental Medicine, UMF Iuliu Hațieganu, Cluj-Napoca
} 
and neonatal phenotype as well as the development of certain pathologies [1].

In the contemporary world, cardiovascular diseases are the main cause of death for both sexes. Epidemiological studies suggest a link between low birth weight and high rates of adult mortality and cardiovascular morbidity, supported by clinical studies showing that intrauterine growth restriction (IUGR) causes adaptative cardiovascular changes [2].

\section{Methods}

This paper is a review of the literature on the long-term effects of intrauterine growth restriction (IUGR) on adult cardiovascular diseases and the mechanisms involved in intrauterine programming and its critical stages. For its elaboration, 20 articles were selected and the conclusions and the results were synthesized and presented in this paper.

\section{Result and discussion}

Critical stages of genetic programming and the mechanism of intrauterine programming

Dynamic and inherited changes that alter the structure of chromosomes, but not the sequence of genes, are defined as epigenetic changes which regulate the expression of line-specific genes in some cellular processes, including the pathogenesis of disease. They also are a reflection of the interaction between DNA and environmental factors. Gene expression depends, partially, on the accessibility of genomic regions such as promoters, enhancers, and silencers [3]. These regions are essential for binding transcriptional factors, such as DNAactivating and repressing proteins, when regulating gene transcription. Acetylation and methylation of histones have major impact in the accessibility of these genomic loci [3]. In general, acetylation of histones in lysine residues is associated with the activation of gene expression, while methylation may be associated with either transcriptional repression or activation, depending on the gene specificity [6]. DNA methylation to certain cytosine regions of the promoter called $\mathrm{CpG}$ islands is another form of epigenetic modification that regulates gene expression. Gene expression can also be regulated by non-coding RNAs; these expression profiles of small molecules can be correlated with the up-regulation or suppression (down-relegation) of specific genes.

Environmental aggressors cause changes in the programming of the fetal phenotype, when they act during the developing stage, and even more, in certain key points, when they will put their mark even more strongly on the postnatal evolution.

In the preconceptional or preimplantational period, oxygen levels, nutrients and hormone levels interfere with the development of the oocyte and further with the blastocyst, affecting the cell distribution between the trophoblast and the rest of the embryonic cell mass [3]. In animal models, it has been shown that contraceptive exposure to elevated levels of progesterone or metabolites such as urea, leads to above average birth weight. At the same time, dietary restrictions during the contraceptive period seem to shorten the duration of pregnancy, and also to cause maternal hypertension and dysfunctions in the hypothalamic-pituitary axis [4]. Changes 
before the implantation of the egg affect multiple cell lines, even if during the pregnancy there are compensatory changes such as up-regulation of transplacental transport. With the onset of placenta formation, intrauterine programming is performed to support its development [5]. Harmful factors that act during organogenesis, produce discrete structural alterations, but permanent and with longterm effects, affecting the functional capacity of the organ in question.

If aggression occurs during gametogenesis, the reproductive potential of the next generation is compromised [6]. If the pathological changes occur during the period of rapid fetal growth and affect the intake and use of nutrients, tissue growth suffers, therefore, the cell cycle moves from the proliferation phase to the differentiation phase, resulting a decrease in the total number of cells $[7,8]$. Given the fact that tissues and organs have different growth rates, pathological changes that occur during intrauterine life affect morphologically and especially functionally various structures when they appear in the latter part of pregnancy. This is due to overlapping with the maturation processes of the fetal organism and its preparation for extrauterine life. Maturation and differentiation processes are mainly glucocorticoid-dependent and can be activated prematurely by early exposure to corticosteroids. Physiological systems of extrauterine maturation and adaptation, that are latent during pregnancy, are normally activated during birth, so that their early activation, in relation to the moment of birth, can have negative effects on the starting point of the health of the newborn.
Intrauterine programming can begin at any level of the affected system and consists of structural and functional changes in genes, cells, tissues and finally organs.

\section{The relation between cardiovascular diseases and intrauterine growth restriction}

The subclinical stage of cardiovascular diseases has an early onset, with some studies suggesting it before birth, the risk factor in this case being the restriction of intrauterine growth. Epidemiological studies have shown that low birth weight is associated with an increased risk of myocardial infarction $[9,10]$, hypertension [11-13], low glucose tolerance and noninsulin-dependent diabetes [14-16]. The biological phenomena underlying these associations are called "fetal programming" and represent structural, metabolic and functional changes that occur as an adaptive response to environmental factors that negatively influence fetal development, these changes persisting in the postnatal period.

In relation to cardiovascular diseases, fetal programming involves metabolic changes and cardiovascular remodeling. Metabolic changes have been implied as the first hypothesis to explain the relationship between adult cardiovascular diseases and low birth weight. The caloric restriction and, implicitly, of nutrients during the epigenetic programming period, especially during the intrauterine life, determine the development of some ways that compensate the alterations produced by them by selecting some "saving" genes [17-19].

Because nutrient availability will be within normal limits in postnatal life, this 
fetal programming will promote a higher incidence of metabolic diseases such as obesity and diabetes but also a metabolic syndrome that can secondarily lead to cardiovascular diseases (CVD) [20,21]. Although metabolic changes are factors that contribute to the determination of $C V D$, they cannot per se explain the epidemiological association between IUGR and CVD [22].

\section{Cardiovascular remodeling and adaptative cardiovascular changes in IUGR}

Placental insufficiency has two major effects on fetal development of the cardiovascular system. Firstly, the reduced intake of oxygen and nutrients disrupts the growth of cardiomyocytes and the architecture of muscle fibers and secondly, villous hypoplasia causes an increased placental resistance and chronic cardiac load [23]. Thus, the developing myocardium shows a variety of changes in micro- and macrostructure and cardiac function which are defined as cardiac remodeling in order to maintain ventricular flow [23]. Initially, the heart has a spheroidal shape that allows the systolic volume to be maintained under a lower contractile force, while reducing the parietal stress in order to better tolerate a pressure overload $[24,25]$. This occurs either in both ventricles (globular phenotype) or in one ventricle (elongated phenotype, where the right globular ventricle pushes the interventricular septum and lengthens the left ventricle). In more severe cases, increased sphericity is not enough and muscle hypertrophy develops over time to increase contractility and reduce parietal stress. Thus, cardiomegaly is a characteristic change with 3 different phenotypes (elongated, globular and hypertrophic) suggesting a progression of severity [25]. Early-onset IUGR is associated with hypertrophic changes while late-onset IUGR causes elongated or globular phenotypes [25]. Cardiac morphometric evaluation such as sphericity index may be more useful in such cases for the evaluation of cardiovascular remodeling compared to functional parameters.

$M$ mode and tissue Doppler show reduced longitudinal myocardial movements [26] that reflect subclinical systolic dysfunction. Diastolic dysfunction occurs in the early stages as increased pulsatility in the venous duct and abnormal E/A ratios [26, 27]. Recent studies show that biomarkers of cardiac dysfunction such as NT-proBNP and those that reflect heart injury such as troponin, have high levels in the umbilical cord blood of girls with IUGR in both early and late onset [28-30]. Echocardiography in newborns with IUGR shows changes similar to intrauterine modifications that include cardiac morphometric changes (dilated left atrium, intraventricular septal hypertrophy), diastolic (increased E/A ratio), and systolic changes (reduced contractility and low cardiac output) [30]. Some studies have reported global longitudinal deformity in the first 5 days of life and also systolic and diastolic heart dysfunction [31, 32].

Cardiovascular changes associated with IUGR persist in childhood, with early and late forms being associated with cardiac remodeling, with globular hearts and reduced longitudinal movements and myocardial relaxation disorders [29]. Children with late onset IUGR show reduced longitudinal movements apparently offset by increased radial function [33]. In severe cases, it is no 
longer compensated so it reduces the systolic volume and is accompanied by a compensatory increase in heart rate to keep the arterial pressure within normal limits. Vascular changes include microvascular endothelial dysfunction and increased blood pressure [33]. A recent study shows that cardiac remodeling persists into preadolescence with spherical ventricles and reduced arterial pressure [34]. Another study shows low aortic size in young adults born with severe IUGR [35].

There are limited data on cardiovascular changes in adults. A study of a cohort of 3596 subjects aged 34-49 years showed a reduction in systolic volume but normal sphericity index values and normal diastolic function. Another study showed a slightly increased systolic blood pressure.

\section{Placental phenotype and hypertension}

The development of hypertension is determined by the lack of sufficient nutrient intake in the uterine life but also by the surface and the shape of the placenta. A study conducted in Bristol, UK, on 13,971 births, found the relationship between the number of placental lobes on the mother's side and blood pressure in 9year-olds as a result of these pregnancies [36]. A number of lobes between 4 and 10 is associated with high blood pressure in these children. In terms of gender distribution, in boys, the number of lobes was described as directly proportional to increased systolic and diastolic blood pressure, without an increased pulse pressure. As a consequence, the number of placental lobes becomes an important index in assessing the long-term risk of developing hypertension.
A Swedish study concluded that low birth weight men developed high blood pressure, with a predominance of diastolic hypertension. [37]. In 10-year-olds with low birth weights, an increased blood pressure and pulse at rest were found. These children and their mothers had a lower height than the population group from which they came, associating the genetic component, in addition to the environmental one [38]. Another Danish study reported the negative effect of IUGR and rapid weight gain up to the age of 7 , targeting obesity and hypertension [39].

Huxley, through his study, established an inversed proportionality between systolic blood pressure, weight and cranial circumference at birth. In fact, his study proposes accelerated postnatal growth as a factor which promotes adult hypertension [40]. In order to start from the origin of the previous arterial hypertension changes, the intrauterine factors have been intensively researched. Hypoprotein diets have been shown to increase peripheral vascular resistance, with a low ventricular rate, in the absence of cardiac hypertrophy [41]. A nonspecific reduction in maternal nutritional intake was shown to be less unfavorable than specific protein deficiency [42-47]. The maternal protein deficiency associated with Omega 3, unsaturated fatty acids, from conception to week 9 of gestation, was materialized in the increase of blood pressure in experimental studies in rats [48]. Another premise for hypertension is maternal malnutrition in the preimplantation period, which acts through genetic regulatory mechanisms. The maternal diet must contain a donor of methyl groups for DNA methylation, the way in which the genetic material is formed is imposed from the first days 
after fertilization. In this way, the preimplantation period can also be considered as a "critical period" in embryonic development. The ideal conditions are to ensure optimal serum levels of folate and low homocysteine during the period of conception.

\section{Chronic cardiac failure}

The relevance of epigenetics in adapting to chronic heart failure (CHF) has been highlighted in adults by the presence of specific prints of DNA changes in heart cells $[49,50]$. A recent analysis of DNA methyloma in cardiomyocytes from healthy adults and adults with CHF shows the dominant role of DNA methylation as a reversible and dynamic process in the development of cardiomyocytes [51]. In intrauterine life, a recent study shows that the treatment of laboratory animals with hypoxia causes hypermethylation of DNA, which is associated with the early transition from mononuclear to binucleate cardiomyocytes and an increased risk of ischemic injury [52]. Data on the reduced length of sarcomeres that negatively influence circulatory dynamics have been reported [53]. Other studies have detailed the mechanism of chronic hypoxia that has led to changes in cardiac structure and function by increasing collagen production [54], cardiomyocyte proliferation and apoptosis and postnatal changes in protein isoforms involved in sarcomeric structure (tinin, myosin) $[55,56,57]$.

\section{Ischemic heart disease and myocardial infarction}

Based on observational studies, it has been hypothesized that newborn males with the lowest birth and at-one-year weights have the highest chance of dying from ischemic coronary heart disease as adults [58]. Although this link is valid for all newborns, cardiovascular diseases secondary to intrauterine growth restriction occur predominantly in men [59]. In a retrospective study of adult men, the concentric dilatation of the left ventricle was found to be a predictor of coronary heart disease [60].

\section{The renin-angiotensin-aldosterone system} (RAAS)

The fetal renin-angiotensin-aldosterone system is activated by IUGR [61]. This dysfunction tends to persist in adults born with IUGR, maintaining the same pattern throughout life. Surprisingly, the predisposition developed in intrauterine life by hypertension seems to have other developing mechanisms than the activation of RAAS [62].

An explanation for the low plasma renin values in girls with IUGR is the nephron deficiency demonstrated in these individuals. The study conducted by Multiple studies concluded that IUGR is associated with a lower number of nephrons, which leads to increased pressure in the glomerular capillaries and secondary to glomerular sclerosis $[63,64]$. This sclerosis further reduces the number of nephrons and thus forms a vicious circle of self-sustaining hypertension. Studies using fetal ultrasonography as main tool of research, have shown reduced kidney growth between weeks 26-34. The reduced renal dimensions are based on the decrease of the antero-posterior diameter and not on their length [65]. Based on these premises, hypertension would only be an adaptation for maintaining homeostasis [66]. 
Related to the cardiovascular system, IGF-1 is an important factor in the growth of blood vessels [67] and this may explain the relationship between rapid postnatal weight growth and the development of hypertension in adulthood.

Reduced compliance of the aorta is an important marker of cardiovascular disease [68], being associated with hypertension and also with left ventricular hypertrophy $[69,70]$. A study performed on a group with a mean age of 50 years, correlated low birth weight with a low compliance of the large arteries accessible to direct examination, respectively at the level of the lower limbs [71]. This vascular deficiency is similarly started and programmed in the intrauterine life, with the formation and distribution of elastin. IUGR associates a reduced amount of elastin in the arteries, which become more rigid, increasing vascular resistance [72-74]. The most important areas in which the effects of this vascular deficit become significant are the descending aorta and the cerebral vascularization [75]. The mechanism responsible for these vascular changes is the centralization of circulation, due to the suboptimal blood supply to the fetus and the adaptation of the cardiovascular system to protect the brain to detriment of other organs and systems [76-78].

\section{Vascular dysfunction}

Systemic vascular resistance is a factor that regulates homeostasis and blood pressure and is heavily dependent on the permeability of peripheral blood vessels. Increases in peripheral vascular resistance are correlated with increases in blood pressure. Some studies have reported that restriction of intrauterine growth is associated with increased vascular resistance. In both, human and laboratory animals, IUGR causes altered blood vessel structure, increased thickness of the intima, [79] and proliferation of smooth muscle cells $[80,81]$.

The vascular response to physiological vasoactive compounds is an important determinant of the regulation of blood pressure and the risk of developing hypertension [82]. In some animal models with IUGR, the unfavorable maternal environment variably affects the response of different vascular beds to physiological vasodilators and vasoconstrictors [83]. Pathologies such as maternal obesity, endothelial nitric oxide synthase deficiency (eNOS) and dexamethasone exposure in animal models have increased the response of adrenergic agents to the mesenteric artery [84-86].

Increased sympathetic activity due to fetal growth restriction, especially in the kidneys, causes desensitization of adrenergic receptors due to increased circulating levels of catecholamines [86]. At the same time, a diet rich in carbohydrates, exposure to dexamethasone and nicotine can cause these desensitizations, which can lead to high blood pressure [87].

Females are protected from this phenomenon unless ovarectomy is performed [88]. Vasodilator substances such as eNOS, prostaglandins and endothelial-dependent hyperpolarization may be mechanisms altered by intrauterine growth restriction and are responsible for reducing the integrity of vascular endothelial function in those with IUGR [89, 90].

The above evidence suggests that there is a correlation between intrauterine growth restriction and the development of 
cardiovascular disease (CVD) in adults with a history of IUGR. However, it is difficult to assess the environmental factors that interact with the human body and how this combination of factors determines a predisposition to cardiovascular disease. The hypothesis that genetic and epigenetic factors invariably require another triggering factor for the manifestation of clinical stage of CVD is well accepted in the field of oncology. Therefore, it can be stated that cardiac remodeling present in IUGR, which is a subclinical stage, involves an increased predisposition to cardiovascular damage, but must be associated with other risk factors, is not a sine qua non condition in adult CVD.

Another topic of interest is the existence of "windows of opportunity" which represent moments during intrauterine life when stopping / reducing certain environmental factors can cause the involution of phenomena induced by IUGR [23]. As shown in animal models, changes in metabolism or epigenetic patterns that are caused by prenatal exposure are correctable if taken early. Whether or not there is a "window of opportunity", the evidence suggests that early intervention has strong positive effects on the evolution of these cardiovascular changes.

Observational and in-vivo studies have shown that breastfeeding and the consumption of polyunsaturated fats during childhood have benefits in terms of vascular remodeling in individuals born with IUGR [91]. Similarly, consumption of eicosapentaenoic acid and alpha-linoleic acid has beneficial effects on children and adolescents born with IUGR but has no effect on those with normal birth-weight [92].
The challenge for future studies in this field is to establish ways in which fetal cardiovascular programming can induce adult cardiovascular disease. Although the evidence supports this statement, the identification of specific groups with high risk and finding the mechanisms of action of the environmental factors that promote accelerated progression to CVD in subjects with IUGR could influence the therapeutic attitude in some cases, even the lifequality in adulthood. Given that IUGR affects $5-10 \%$ of the total number of pregnancies [93], the possibility of reducing morbidity in some cases would be an important step in the medical field.

\section{Conclusions}

IUGR has a strong influence on cardiovascular health and the identification of prenatal risk factors can implement preventive strategies that lead to the reduction of morbidity and mortality through this pathogenesis. Whether there are specific subgroups in which differences related to IUGR-induced changes persist or worsen remains a question that requires further study.

\section{References}

1. Kitsiou-Tzeli S, Tzetis M. Maternal epigenetics and fetal and neonatal growth. Current Opinion in Endocrinology \& Diabetes and Obesity 2017;24(1): 43-46

2. Li S, Chen W, Srinivasan SR, et al. Childhood cardiovascular risk factors and carotid vascular changes in adulthood: the Bogalusa Heart Study. JAMA 2003; 290:2271-6.

3. Brantsaeter AL, Myhre R, Haugen $M$, Myking $S$, Sengpiel $V$, Magnus $P$, 
Jacobsson B, Meltzer HM. Intake of probiotic food and risk of preeclampsia in primiparous women: the Norwegian Mother and Child Cohort Study. American journal of epidemiology. 2011; 174, 807-815.

4. Chaddha V, Viero S, Huppertz B, Kingdom J. Developmental biology of the placenta and the origins of placental insufficiency. Semin Fetal Neonatal Med 2004;9,357-369.

5. Poston L, McCarthy AL, Ritter JM. Control of vascular resistance in the maternal and feto-placental arterial beds. Pharmacology \& therapeutics 1995; 65,215-239.

6. Kublickiene KR, Cockell AP, Nisell $H$, Poston L. Role of nitric oxide in the regulation of vascular tone in pressurized and perfused resistance myometrial arteries from term pregnant women. American journal of obstetrics and gynecology 1997; 177,1263-1269.

7. Casanello P, Sobrevia L. Intrauterine growth retardation is associated with reduced activity and expression of the cationic amino acid transport systems $y+/$ hCAT- 1 and $y+/$ hCAT-2B and lower activity of nitric oxide synthase in human umbilical vein endothelial cells. Circ Res 2002; 91, 127-134.

8. Schiessl B, Strasburger C, Bidlingmaier $M$, Mylonas I, Jeschke $U$, Kainer $F$, Friese K. Plasma- and urine concentrations of nitrite/nitrate and cyclic Guanosinemonophosphate in intrauterine growth restricted and preeclamptic pregnancies. Arch Gynecol Obstet 2006;274,150-154.

9. Barker DJP, Osmond C, Winter PD, Margetts B, Simmonds SJ. Weight in infancy and death from ischaemic heart disease. Lancet 1989; 334:57780.

10. Rich-Edwards JW, Stampfer MJ, Manson JE, et al. Birth weight and risk of cardiovascular disease in a cohort of women followed up since 1976. BMJ 1997;315:396-400.

11. Law CM, Shiell AW. Is blood pressure inversely related to birth weight? The strength of evidence from a systematic review of the literature. $J$ Hypertens 1996; 14:935-41.

12. Leon DA, Koupilova I, Lithell HO, et al. Failure to realise growth potential in utero and adult obesity in relation to blood pressure in 50 year old Swedish men. BMJ 1996;312:401-6.

13. Barker DJ, Hales $\mathrm{CN}$, Fall $\mathrm{CH}$, et al. Type 2 (non-insulin-dependent) diabetes mellitus, hypertension and hyperlipidaemia (syndrome $\mathrm{X}$ ): relation to reduced fetal growth. Diabetologia 1993; 36:62-7.

14. Barker DJ, Hales $\mathrm{CN}$, Fall $\mathrm{CH}$, et al. Type 2 (non-insulin-dependent) diabetes mellitus, hypertension and hyperlipidaemia (syndrome $\mathrm{X}$ ): relation to reduced fetal growth. Diabetologia 1993;36:62-7.

15. Hales CN, Barker DJ, Clark PM, et al. Fetal and infant growth and impaired glucose tolerance at age 64. BMJ 1991; 303:1019-22.

16. Lithell HO, McKeigue PM, Berglund L, et al. Relation of size at birth to noninsulin dependent diabetes and insulin concentrations in men aged $50-60$ years. BMJ 1996; 312:406-10.

17. Neel JV. Diabetes mellitus: a "thrifty" genotype rendered detrimental by "progress"? Am J Hum Genet 1962; 14:353-62.

18. Hales CN, Barker DJ. Type 2 (noninsulindependent) diabetes mellitus: 
the thrifty phenotype hypothesis. Diabetologia 1992;35: 595-601.

19. Gluckman PD, Hanson MA. Living with the past: evolution, development, and patterns of disease. Science 2004;305:1733-6.

20. Gluckman PD, Hanson MA, Cooper C, Thornburg KL. Effect of in utero and early-life conditions and adult health and disease. $N$ Engl J Med 2008;359:61-73.

21. Bateson P, Barker D, Clutton-Brock T, et al. Developmental plasticity and human health. Nature 2004; 430:41921.

22. Kuzawa CW. Fetal origins of developmental plasticity: Are fetal cues reliable predictors of future nutritional environments? Am J Hum Biol 2005;17:5-21.

23. Crispi F, Miranda J, Gratacós, E. Longterm cardiovascular consequences of fetal growth restriction: biology, clinical implications, and opportunities for prevention of adult disease. American Journal of Obstetrics and Gynecology. 2018; 218(2), S869-S879

24. Tsyvian P, Malkin K, Wladimiroff JW. Assessment of fetal left cardiac isovolumic relaxation time in appropriate and small-forgestationalage fetuses. Ultrasound Med Biol 1995;21:739-43.

25. Rodríguez-López $M$, Cruz-Lemini $M$, Valenzuela-Alcaraz B, et al. Descriptive analysis of the different phenotypes of cardiac remodeling in fetal growth restriction. Ultrasound Obstet Gynecol 2016; 109:2079-88.

26. Crispi F, Gratacos E. Fetal cardiac function: technical considerations and potential research and clinical applications. Fetal Diagn Ther 2012; 32:47-64.
27. Hernandez-Andrade E, Benavides Serralde JA, Cruz-Martinez R, Welsh A, Mancilla-Ramirez J. Evaluation of conventional Doppler fetal cardiac function parameters: E/A ratios, outflow tracts, and myocardial performance index. Fetal Diagn Ther 2012;32:22-9

28. Comas M, Crispi F, Cruz-Martinez R, Figueras F, Gratacos E. Tissue Doppler echocardiographic markers of cardiac dysfunction in small-for-gestational age fetuses. Am J Obstet Gynecol 2011;205:57.e1-6.

29. Crispi F, Hernandez-Andrade E, Pelsers MMAL, et al. Cardiac dysfunction and cell damage across clinical stages of severity in growth-restricted fetuses. Am J Obstet Gynecol 2008; 199:254.e1-8.

30. Girsen A, Ala-Kopsala M, Mäkikallio K, Vuolteenaho $O$, Räsänen J. Cardiovascular hemodynamics and umbilical artery $\mathrm{N}$-terminal peptide of proB-type natriuretic peptide in human fetuses with growth restriction. Ultrasound Obstet Gynecol 2007;29: 296-303

31. Sehgal A, Doctor T, Menahem S. Cardiac function and arterial indices in infants born small for gestational age: analysis by speckle tracking. Acta Paediatr 2014;103:e49-54. 77.

32. Altin H, Karaarslan S, Karatas, Z, et al. Evaluation of cardiac functions in term small for gestational age newborns with mild growth retardation: a serial conventional and tissue Doppler imaging echocardiographic study. Early Hum Dev 2012; 88:757-64.

33. Martin H, Hu J, Gennser G, Norman M. Impaired endothelial function and increased carotid stiffness in 9-year- 
old children with low birthweight. Circulation 2000;102:2739-44

34. Sarvari SI, Rodriguez-Lopez M, Nuñez Garcia M, et al. Persistence of cardiac remodeling in preadolescents with fetal growth restriction. Circ Cardiovasc Imaging 2017; 10

35. Bjarnegård $N$, Morsing $E$, Cinthio $M$, Länne T, Brodszki J. Cardiovascular function in adulthood following intrauterine growth restriction with abnormal fetal blood flow. Ultrasound Obstet Gynecol 2013;41:177-84.

36. Buckberry S, Bianco-Miotto T, Bent SJ, Dekker GA, Roberts CT. Integrative transcriptome meta-analysis reveals widespread sex-biased gene expression at the human fetalmaternal interface. Mol Hum Reprod 2014;20: 810-819.

37. Sood R, Zehnder JL, Druzin ML, Brown PO. Gene expression patterns in human placenta. Proc Natl Acad Sci USA 1996;103: 5478-5483.

38. Cvitic $S$, Longtine $M S$, Hackl $H$, Wagner $\mathrm{K}$, Nelson MD, Desoye G, Hiden U. The human placental sexome differs between trophoblast epithelium and villous vessel endothelium. PLoS One 2013;8:e79233.

39. Goenezen S, Rennie MY, Rugonyi S. Biomechanics of early cardiac development. Biomech Model Mechanobiol 2012;11: 1187-1204.

40. Hogers B, DeRuiter MC, Gittenbergerde Groot AC, Poelmann RE. Unilateral vitelline vein ligation alters intracardiac blood flow patterns and morphogenesis in the chick embryo. Circ Res 1997;80: 473-481.

41. Lindsey SE, Butcher JT, Yalcin HC. Mechanical regulation of cardiac development. Front Physiol 2014; 5: 318.
42. Midgett $M$, Rugonyi S. Congenital heart malformations induced by hemodynamic altering surgical interventions. Front Physiol 2014; 5: 287.

43. Molteni RA, Stys SJ, Battaglia FC. Relationship of fetal and placental weight in human beings: fetal/placental weight ratios at various gestational ages and birth weight distributions. J Reprod Med 1978;21: 327-334.

44. Salafia CM, Zhang J, Miller RK, Charles $A K$, Shrout $P$, Sun W. Placental growth patterns affect birth weight for given placental weight. Birth Defects Res A Clin Mol Teratol 2007; 79: 281-288.

45. Eriksson JG, Kajantie E, Phillips DI, Osmond C, Thornburg KL, Barker DJ. The developmental origins of chronic rheumatic heart disease. Am J Hum Biol 2013; 25: 655-658.

46. Challier JC, Basu S, Bintein T, Minium J, Hotmire K, Catalano PM, Hauguel-de Mouzon S. Obesity in pregnancy stimulates macrophage accumulation and inflammation in the placenta. Placenta 2008;29: 274-281.

47. Redline RW. Placental inflammation. Semin Neonatol 2004;9: 265-274.

48. Mestan K, Yu Y, Matoba N, Cerda S, Demmin B, Pearson C, Ortiz K, Wang $X$. Placental inflammatory response is associated with poor neonatal growth: preterm birth cohort study. Pediatrics 2010;125: e891-898.

49. Haas J, Frese KS, Park YJ, et al. Alterations in cardiac DNA methylation in human dilated cardiomyopathy. EMBO Mol Med 2013;5:413-29.

50. Movassagh M, Choy MK, Knowles DA, et al. Distinct epigenomic features in 
end-stage failing human hearts. Circulation 2011;124: 2411-22

51. Gilsbach R, Preissl S, Grüning BA, et al. Dynamic DNA methylation orchestrates cardiomyocyte development, maturation and disease. Nat Commun 2014;5:5288.

52. Paradis A, Xiao D, Zhou J, Zhang L. Endothelin-1 promotes cardiomyocyte terminal differentiation in the developing heart via heightened DNA methylation. Int J Med Sci 2014; 11:373-80.

53. Iruretagoyena JI, Gonzalez-Tendero A, Garcia-Canadilla $P$, et al. Cardiac dysfunction is associated with altered sarcomere ultrastructure in intrauterine growth restriction. $\mathrm{Am} \mathrm{J}$ Obstet Gynecol 2014;210:550.e1-7.

54. Bae S, Xiao Y, Li G, Casiano CA, Zhang L. Effect of maternal chronic hypoxic exposure during gestation on apoptosis in fetal rat heart. Am J Physiol Heart Circ Physiol 2003;285: H983-90.

55. Tintu A, Rouwet $E$, Verlohren $S$, et al. Hypoxia induces dilated cardiomyopathy in the chick embryo: mechanism, intervention, and longterm consequences. PLoS One 2009;4: e5155.

56. Rueda-Clausen CF, Morton JS, Lopaschuk GD, Davidge ST. Long-term effects of intrauterine growth restriction on cardiac metabolism and susceptibility to ischaemia reperfusion. Cardiovasc Res 2011;90:285-94.

57. Xu Y, Williams SJ, O'Brien D, Davidge ST. Hypoxia or nutrient restriction during pregnancy in rats leads to progressive cardiac remodeling and impairs postischemic recovery in adult male offspring. FASEB J 2006; 20:12513

58. Barker DJP, Hales CN, Fall CHD, Osmond C, Phipps K, and Clark PMS. Type 2 (non-insulin-dependent) diabetes mellitus, hypertension and hyperlipidemia (syndrome $\mathrm{X}$ ): relation to reduced fetal growth. Diabetologia 36: 62-67, 1993.

59. Gennser G, Rymark, Isberg PE. Low birth weight and risk of high blood pressure in adulthood. Bone Miner J 1988;296: 1498-1500.

60. Barker DJ, Osmond C, Golding J, Kuh D, Wadsworth ME. Growth in utero, blood pressure in childhood and adult life, and mortality from cardiovascular disease. Bone Miner J 1989; 298: 564567.

61. Schack-Nielsen L, Holst C, Sorensen TI. Blood pressure in relation to relative weight at birth through childhood and youth in obese and non-obese adult men. Int J Obes Relat Metab Disord 2002;26: 1539-1546.

62. Huxley RR, Shiell AW, Law CM. The role of size at birth and postnatal catch-up growth in determining systolic blood pressure: a systematic review of the literature. J Hypertens 2000;18: 815-831.

63. Hinchliffe SA, Lynch MR, Sargent PH, Howard CV, Van Velzen D. The effect of intrauterine growth retardation on the development of renal nephrons. $\mathrm{Br} J$ Obstet Gynaecol. 1992;99(4): 296-301.

64. Zohdi V, Sutherland MR, Lim K, Gubhaju L, Zimanyi MA, Black MJ. Low Birth Weight due to Intrauterine Growth Restriction and/or Preterm Birth: Effects on Nephron Number and Long-Term Renal Health. Int J Nephrol. 2012;2012:136942 
65. Ozaki T, Nishina H, Hanson MA, Poston L. Dietary restriction in pregnant rats causes gender-related hypertension and vascular dysfunction in offspring. J Physiol 2001; 530: 141-152.

66. Vickers $\mathrm{MH}$, Breier $\mathrm{BH}$, Cutfield WS, Hofman PL, Gluckman PD. Fetal origins of hyperphagia, obesity, and hypertension and postnatal amplification by hypercaloric nutrition. Am J Physiol Endocrinol Metab 2000; 279: E83-E87.

67. Osmond C, Barker DJP, Winter PD, Fall $\mathrm{CHD}$, Simmonds SJ. Early growth and death from cardiovascular disease in women. Bone Miner J 1993;307: 1519-1524.

68. Vijayakumar $\mathrm{M}$, Fall $\mathrm{CH}$, Osmond $\mathrm{C}$, Barker DJ. Birth weight, weight at one year, and left ventricular mass in adult life. Br Heart J 1995;73: 363-367.

69. Margetts BM, Rowland MGM., Foord FA, Cruddas AM, Cole TJ, Barker DJP. The relation of maternal weight to the blood pressures of Gambian children. Int. J. Epidemiol. 1991;20:938-943.

70. Campbell DM, Hall MH, Barker DJP, Cross J, Shiell AW, Godfrey KM. Diet in pregnancy and the offspring's blood pressure 40 years later. Br. J. Obstet. Gynaecol. 1996;103, 273-280.

71. Kingdom JCP, McQueenJ, Connell JMC, Whittle MJ. Fetal angiotensin II levels and vascular (Type 1) angiotensin receptors in pregnancies complicated by intrauterine growth retardation. $\mathrm{Br}$. J. Obstet. Gynaecol. 1993;100, 476482.

72. Mackenzie HS, Brenner BM. Fewer nephrons at birth: a missing link in the etiology of essential hypertension? Am. J. Kidney Dis. 1995;26, 91-98.
73. Brenner BM, Chertow GM. Congenital oligonephropathy: an inborn cause of adult hypertension and progressive renal injury? Curr. Opin. Nephrol. Hypertens. 1993; 2, 691-695.

74. Konje JC, Bell SC, Morton JJ, de Chazal $\mathrm{R}$,Taylor DJ. Human fetal kidney morphometry during gestation and the relationship between weight, kidney morphometry and plasma active renin concentration at birth. Clin. Sci. 1996;91, 169-175.

75. Weder AB, Schork, NJ. Adaptation, allometry, and hypertension. Hypertension 1994;24, 145-156.

76. Edwards CRW, Benediktsson $R$, Lindsay RS, Seckl JR. Dysfunction of placental glucocorticoid barrier: link between fetal environment and adult hypertension? Lancet 1993; 341, 355-357.

77. Seckl JR. Glucocorticoids and small babies. Q. J. Med. 1994; 87, 259-262.

78. Clark PM, Hindmarsh PC, Shiell AW, Law CM, Honour JW, Barker DJP. Size at birth and adrenocortical function in childhood. Clin. Endocrinol. 1996;45, 721-726.

79. Crispi F, Figueras F, Cruz-Lemini $M$, Bartrons J, Bijnens B, Gratacos E. Cardiovascular programming in children born small for gestational age and relationship with prenatal signs of severity. Am J Obstet Gynecol. 2012 Aug; 207(2):121.e1-9.

80. Armitage JA, Lakasing L, Taylor PD, et al. Developmental programming of aortic and renal structure in offspring of rats fed fat-rich diets in pregnancy.J Physiol. 2005; 565:171184.

81. Khorram $O$, Momeni $M$, Ferrini $M$, Desai M, Ross MG. In utero undernutrition in rats induces 
increased vascular smooth muscle content in the offspring. Am J Obstet Gynecol. 2007;196: 486.e1-486.e8.

82. Touyz RM, Alves-Lopes R, Rios FJ, et al. Vascular smooth muscle contraction in hypertension. Cardiovasc Res. 2018; 114:529-539.

83. Morton JS, Cooke C-L, Davidge ST. In utero origins of hypertension: mechanisms and targets for therapy. Physiol Rev. 2016; 96(2):549e603.

84. Samuelsson A-M, Matthews PA, Argenton $M$, et al. Diet-induced obesity in female mice leads to offspring hyperphagia, adiposity, hypertension, and insulin resistance. Hypertension. 2008;51:383-392.

85. Roghair RD, Segar JL, Volk KA, et al. Vascular nitric oxide and superoxide anion contribute to sex-specific programmed cardiovascular physiology in mice. Am J Physiol Regul Integr Comp Physiol. 2009;296:R651R662.

86. O'Regan D, Kenyon CJ, Seckl JR, Holmes MC. Prenatal dexamethasone 'programmes' hypotension, but stressinduced hypertension in adult offspring. J Endocrinol. 2008; 196: 343-352.

87. Xiao D, Dasgupta C, Li Y, Huang X, Zhang L. Perinatal nicotine exposure increases angiotensin II receptormediated vascular contractility in adult offspring. PLOS One. 2014;9:e108161

88. Musha $Y$, Itoh S, Hanson M, Kinoshita K. Does estrogen affect the development of abnormal vascular function in offspring of rats fed a lowprotein diet in pregnancy? Pediatr Res. 2006; 59:784-789.
89. Torrens C, Brawley L, Anthony FW, et al. Folate supplementation during pregnancy improves offspring cardiovascular dysfunction induced by protein restriction. Hypertension. 2006; 47:982-987.

90. Shukla P, Ghatta S, Dubey $N$, et al. Maternal nutrient restriction during pregnancy impairs an endotheliumderived hyper-polarizing factor-like pathway in sheep fetal coronary arteries. Am J Physiol Heart Circ Physiol. 2014;307:H134-H142.

91. Rodriguez-Lopez M, Osorio L, Acosta $R$, et al. Influence of breastfeeding and postnatal nutrition on cardiovascular remodeling induced by fetal growth restriction. Pediatr Res 2016; 79: 100-6.

92. Skilton MR, Raitakari OT, Celermajer DS. High intake of dietary long-chain u-3 fatty acids is associated with lower blood pressure in children born with low birth weight: NHANES 2003-2008. Hypertension 2013;61: 972-6.

93. Nardozza LM, Caetano AC, Zamarian AC, Mazzola JB, Silva CP, Marçal VM, Lobo TF, Peixoto $A B$, Araujo Júnior $E$. Fetal growth restriction: current knowledge. Arch Gynecol Obstet. 2017 May; 295(5): 1061-1077. 